\title{
REPRESENTASI BUDAYA ETNIS PADA PROGRAM TELEVISI ETHNIC RUNAWAY EPISODE SUKU SAMBORI
}

\author{
Aditya Dimas Pratama \\ Program Studi Ilmu Komunikasi, Fakultas Ilmu Sosial dan Ilmu Politik \\ Universitas Muhammadiyah Jember. Jl. Karimata No.49 Jember \\ adityadimas@unmuhjember.ac.id
}

\begin{abstract}
This research presents an ethnic culture in the meaning of denotation, connotation, and myths that appear in episodes of Ethnic Run Away of the Sambori Tribe that broadcasted on Trans TV. The data in this research obtained from Ethnic Run Away television program episode Tribe Sambori which served on Trans TV channel. In discussing on this research, intercultural communication concepts being used and Adorno's thought about non identity in negative dialectics. The result showed that there are five scenes in the impression particulary representative Tribe Sambori. And then from that scenes could be identified that myth about Tribe Sambori such as Sambori is communities from Tribe Bima which live in Sambori village, Bima district, Nusa Tenggara Barat province. Sambori also have the uniqueness of its own, both from history's side and culture. By analyze the sign in the form of audio-visual aspects, this research conclude that the impressions of Ethnic Run Away Episode Tribe Sambori can't be separated from a dominant edilogy likes etnocentrism.
\end{abstract}

Keywords : Ethnic, Semiotics, Representative, Intercultural Communcation, Etnocentrism

\begin{abstract}
Abstrak
Penelitian ini mempresentasikan etnis budaya dalam pemaknaan denotasi, konotasi, serta mitos yang muncul pada segmen tayangan televisi Ethnic Run Away Episode Suku Sambori yang disiarkan Trans TV. Dalam membahas penelitian ini, digunakan konsep-konsep dalam komunikasi antar budaya dan pemikiran Adorno tentang “ nonidentitas" dalam Negative Dialectics. Hasil penelitian ini menunjukkan bahwa terdapat lima adegan dalam tayangan ini yang secara khusus merepresentasikan Suku Sambori. Untuk kemudian, dari adegan-adegan tersebut teridentifikasi mitos-mitos tentang Suku Sambori sebagai berikut ; Sambori adalah komunitas masyarakat bagian dari suku Bima yang bertempat di desa Sambori Kabupaten Bima Provinsi Nusa Tenggara Barat. Serta memiliki keunikan tersendiri baik dari sisi sejarah maupun budayanya. Melalui analisis tanda-tanda berupa aspek visual dan aspek audio, penelitian ini menyimpulkan bahwa tayangan Ethnic Run Away Episode Suku Sambori tidak lepas dari sebuah ideologi dominan, yaitu etnosentrisme.
\end{abstract}

Kata Kunci : Etnis, Semiotika, Representasi, Komunikasi Antarbudaya, Etnosentrism 


\section{Pendahuluan}

Beberapa tayangan televisi nasional memposisikan sebagai tayangan ringan yang menemani pemirsa di setiap harinya. Tetapi hal yang mungkin dianggap ringan dan menghibur terkadang bermasalah. Seperti kasus yang terjadi di tahun 2009 yang dilansir KPI (Komisi Penyiaran Indonesia) memalui website (http://www.kpi.go.id/index.php?option=c om_content\&view=articel\&id=1006\&cati $\mathrm{d}=14 \% 3$ Adalam-negeri-umum\&lang=id, diakses tanggal 17 November 2011). Dalam patauan Komisi Penyiaran Indonesia pada bulan Februari 2010 ada 6 program tayangan televisi yang melanggar dalam pengaduan masyarakat pada bulan Mei 2010 yang mengandung unsur kekerasan fisik, adegan sensual, makian dan vulgar, serta perkataan yang dapat melecehkan fisik maupun suku tertentu.

Belum lama ini bermunculan kasus yang dianggap melecehkan masyarakat adat di Indonesia yang berasal dari salah satu tayangan di Trans TV yang melibatkan public figure artis untuk tinggal menetap di salah satu suku yang ada di Indonesia selama semalam, dalam mengetahui budaya adat istiadat setempat. Program Acara "Primitive Runaway" yang sekarang terlah berganti nama menjadi "Ethnic Runaway”.

Acara ini sebelumnya menayangkan seminggu sekali pada hari Jum'at malam, berganti menjadi setiap Sabtu pukul 15.00-15.30 WIB, dan sekarang pun jam tayanganya ditambah menjadi 2 kali satu minggu, yakni sabtu dan minggu pada pukul 14.00-14.30 WIB. Namun tayangan ini sudah melewati batas pada estetika dalam tayangan yang tujuannya untuk menghibur hingga tayangan ini diekspose di televisi. Menurut Roy Thaniago dalam opini di Koran Tempo edisi 24 November 2010 justru tayangan "Primitive Runaway dianggap telah dikemas sedemikian rupa, justru ada 3 pokok permasalahan, diantaranya :

1. Mendiskriminasi budaya adat dengan menyematkan predikat "primitive".

2. Mensetting realitas kehidupan masyarakat adat, dan

3. Mereproduksi dan menyebarkan kesesatan dalam berpikir mengenai masyarakat adat yang menurutnya penuh kesesatan dan kebohongan.

4. Episode yang akan diangkat dalam penelitian ini ialah Ethnic Runaway episode Suku Sambori yang disiarkan pada tanggal 17 Desember 2010 dan ditayangkan ulang pada tanggal 17 Desember 2012, dengan bintang tamu 
artis Rio Dewanto dan Lia Waode. Sebagai bahan pertimbangan ialah, peniliti ingin melihat program acara ini setelah mengalami perubahan judul acara dari Primitive Runaway menjadi Ethnic Runaway, serta peneliti mengambil episode paling terbaru guna mendapatkan data yang lebih terkini. Hal yang juga menarik dan mendapat perhatian khusus oleh peneliti dalam episode ini ialah karena salah seorang bintang tamu, yakni Lia Waode, ialah sebelumnya terkenal dengan tayangan televisi lenong maupun sinetron. Dalam adegan awal tayangan episode ini, sebelum judul pembuka diperlihatkan rasa menjijikan, serta kuburan tanah keramat nenek moyang Suku Sambori yang tidak boleh di injak oleh siapa pun.

5. Selanjutnya simbol-simbol yang terdapat dalam tayangan televisi ini akan menjadi alat untuk memperlihatkan etnosentrisme dan hubungan antarbudaya di dalamnya. Penelitian ini berusaha memahami makna-makna yang terkandung dalam tanda-tanda yang tersembunyi di program televisi tersebut, juga menyampaikan makna yang dapat dicerna untuk kemudian dipahami sebagai suatu tanda. Metode semiotika yang digunakan adalah metode semiotika Roland Barthes yang berfungsi sebagai pisau bedah untuk menginterpretasikan makna yang terkandung dalam tandatanda tersebut. Lebih lanjut lagi, salah satu episode Ethnic Runaway ini dianalisis dengan memakai dua tahap penandaan (two order of signification) Barthes.

\section{Metode Penelitian}

Penelitian yang digunakan menggunakan jenis penelitian deskriptif kualitatif. Dimana hasil penelitian ini berupa kata-kata tertulis atau lisan dari orang dan perilaku yang diamati.

Pendekatan Kualitatif yang berlandaskan fenomenologi dengan adanya pendekatan holistic dalam sebuah objek penelitian dalam suatu kontruks ganda, serta melihat objeknya dalam suatu konteks natural, bukan parsial.

Hubungan dalam penggunaan metode penelitian ini atas dasar budaya dalam komunikasi yang merupakan proses dalam perubahan serta serangkaian tindakan peristiwa menuju suatu hasil. Komunikasi pada hakikatnya adalah proses penyampaian pesan oleh komunikator kepada komunikan.. Dalam hal ini penelitian dilakukan untuk representasi makna pada program acara televisi dalam Ethnic Runaway. 
Pengumpulan data dilakukan dengan mempergunakan teknik wawancara dan studi dokumentasi akan tetapi yang paling utama adalah melalui metode wawancara. Secara rinci akan dijelaskan sebagai berikut :

a. Wawancara

Wawancara dilakukan secara langsung dengan Bapak Syarifudin bagian fungsi siaran Komisi Penyiaran Indonesia Daerah Jawa Timur. Sebelumnya peneliti menyiapkan daftar pertanyaan sebagai pengumpul data, kemudian diajukan kepada nara sumber. Peneliti mencatat jawaban seperti keadaan seadanya, jadi data yang diperoleh murni dari nara sumber. Selain itu, memungkinkan peneliti untuk menyelingi jawaban nara sumber, hal ini dilakukan untuk meminta penjelasan kembali yang kurang dimengerti. Dalam proses wawancara ini, peneliti menggunakan catatan dan alat rekam demi kelancaran proses wawancara.

\section{b. Studi Dokumentasi}

Peneliti menggali segala data pendukung yang berhubungan dengan obyek penelitian berupa video, arsip, atau catatan mengenai Ethnic Runaway Episode Suku Sambori Nusa Tenggara Barat.
Teknik Analisis Data Kualitatif (Bogdan \& Biklen, 1982) adalah upaya yang dilakukan dengan jalan bekerja dengan data, mengorganisasikan data, memilah-milahnya menjadi satuan yang dapat dikelola, menemukan yang penting dan apa yang dipelajari, dan memutuskan apa yang dapat diceritakan kepada orang lain. (Dalam Moleong hlm : 248, 2012)

a. Reduksi data

Dalam penelitian ini, data atau informasi hasil akhir dari pengumpulan di lapangan ditulis dalam bentuk uraian atau laporan terinci. Uraian-uraian dan laporan tersebut kemudian direduksi, dirangkum, dipilih sesuai dengan pokok-pokok pembahasan sesuai dengan kategori permasalahan. Kemudian, disusun sesuai dengan pembahasan permasalahan secara sistematik sehingga mudah dimengerti.

b. Display Data

Dalam penelitian ini, setelah data tersusun secara sistematik sesuai pengelompokan bahasan, kemudian disusun dalam bentuk penjelasan (narasi) sehingga membentuk rangkaian informasi yang bermakna sesuai dengan permasalahan yang diajukan dalam penelitian ini.

c. Penarikan Kesimpulan

Dalam penelitian ini, peneliti menarik kesimpulan berdasarkan data yang 
diperoleh setelah melewati tahap reduksi dan display data. Kemudian, kesimpulan tersebut akan berisi mengenai data yang telah terangkum berupa laporan dalam bentuk deskriptif.

\section{Hasil Penelitian dan Pembahasan}

$$
\text { Scene Rumah Adat Suku Sambori }
$$

Lengge (Segmen 2)
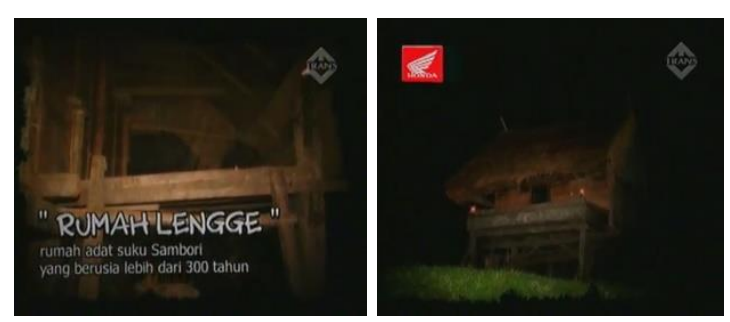

Time Code VCR :00. 10.08.22 -

00.11.07.21

\section{Analisis Denotasi}

Adegan ini memperlihatkan Lia Wa'ode yang tiba-tiba tertarik dengan rumah Lengge berukuran $3 \times 3$ meter, disela-sela pembicaraan tersebut disisipkan video dengan subtittle yang membahas rumah lengge yang usianya mencapai 300 tahun. Setelah itu mereka beranjak melanjutkan kegiatan dengan makan malam khas Suku Sambori Oi’Mangge bersama kedua orang tua angkat.

\section{Analisis Konotasi}

Konotasi yang dimaksud ialah sistem semiologis tingkat kedua (the second order semiological system) menurut
Barthes. Segmen 2 ini dengan menit 00.10.08.22 - 00.11.07.21 menandakan bahwa salah satu adat Suku Sambori, yakni rumah Lengge yang satu rumah berisi ruang tempat memasak dan tempat tidur merupakan hal yang aneh. Ini karena dilihat dari sudut pandang pembawa acara, karena bila diperhatikan lebih jauh lagi yang terjadi pereduksian, karena informasi-informasi penting untuk mendeskripsikan kebiasaan Suku Sambori tersebut tidak tersajikan lengkap dan hanya audio teks saja.

\section{Scene Jamuan Makanan Khas Suku}

\section{Sambori Oi’ Mangge (Segmen 2)}
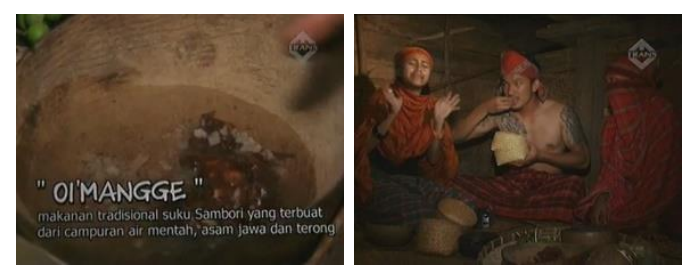

Time Code VCR : 00.11.46.13 -

$$
00.14 .13 .19
$$

\section{Analisis Denotasi}

Adegan ini memperlihatkan Rio Dewanto dan Lia Wa'ode yang terlihat senang menikmati jamuan makan malam oleh kedua orang tua angkat suku sambori, namun reaksi menunjukkan jijik maupun tidak kuat untuk makanan tersebut dalam pengambilan gambar saat jamuan makan malam khas suku Sambori Oi'Mangge. Tampak disana betapa kaku dan 
canggung, ditambah dengan keadaan yang akan muntah. Long Shoot memperlihatkan suasana keadaan makan bersama orang Suku Sambori.

\section{Analisis Konotasi}

Konotasi yang dimaksud ialah sistem semiologis tingkat kedua (the second order semiological system) menurut Barthes. Segmen 2 ini dengan menit 00.11.46.13 - 00.14.13.19 bahwa salah satu adat Suku Sambori, yakni Oi Mangge adalah asam jawa yang dicampur dengan air mentah dan juga ditambah terong kecil sebagai pelengkapnya ada kebiasaaan unik Suku Sambori yaitu mereka mereka terbiasa mengkonsumsi air mentah dari dulu kala. Jika minum dengan air matang akan menyebabkan perut sakit.

\section{Scene Tanah Keramat (Segmen 4)}
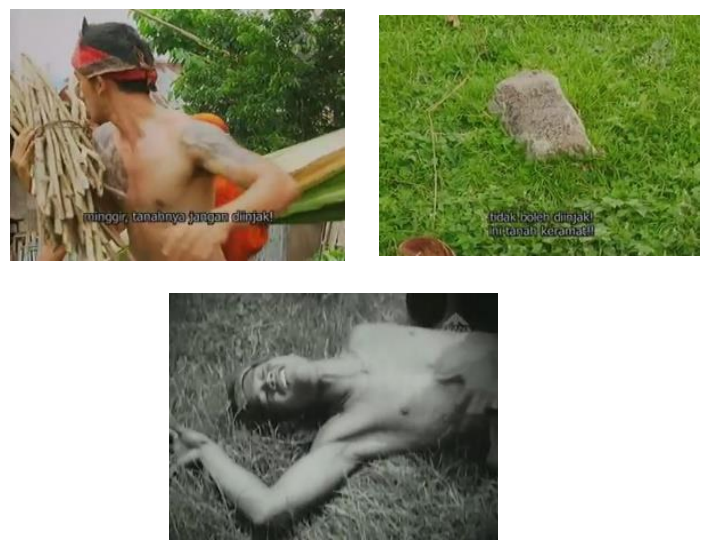

Time Code VCR : 00.26.30.00 -

00.28.00.00

\section{Analisis Denotasi}

Adegan ini memperlihatkan Rio Dewanto dan Lia Wa'ode yang terlihat bagaimana reaksi setelah Irwan dan Wai Hai menegur agar tidak menginjak tanah keramat. Long Shoot memperlihatkan suasana keadaan tanah keramat yang horor.

Tanah Keramat tersebut mulai ada sejak nenek moyang Suku Sambori dimana bagi pendatang maupun yang sengaja menginjak tanah keramat tersebut akan berakibat masuknya roh halus dengan kasat mata yang biasa disebut kesurupan atau Parafumanggoodo.

\section{Analisis Konotasi}

Orang Jakarta menganggap tanah keramat sebagai hal yang ada penunggunya, dimana harus ada tingkah laku yang sopan, sedangkan tidak bagi orang Sambori. Selain itu dilihat dari mana yang dianggap penting dilihat dari bahasa visual dan arti penting yang sebelumnya telah dibahas, terlihat bahwa orang Jakarta ialah penting sedangkan tidak bagi orang Sambori.

Dari kelima kode tersebut, dapat ditarik konotasinya yang dimaksud ialah sistem semiologis tingkat kedua (the second order semiological system) 
menurut Barthes. Segmen 2 ini dengan menit 00.26.30.00 - 00.28.00.00 bahwa Tanah Keramat tersebut mulai ada sejak nenek moyang Suku Sambori dimana bagi pendatang maupun yang sengaja menginjak tanah keramat tersebut akan berakibat masuknya roh halus dengan kasat mata yang biasa disebut kesurupan atau Parafumanggoodo.

\section{Scene Isukami'i (Segmen 4)}
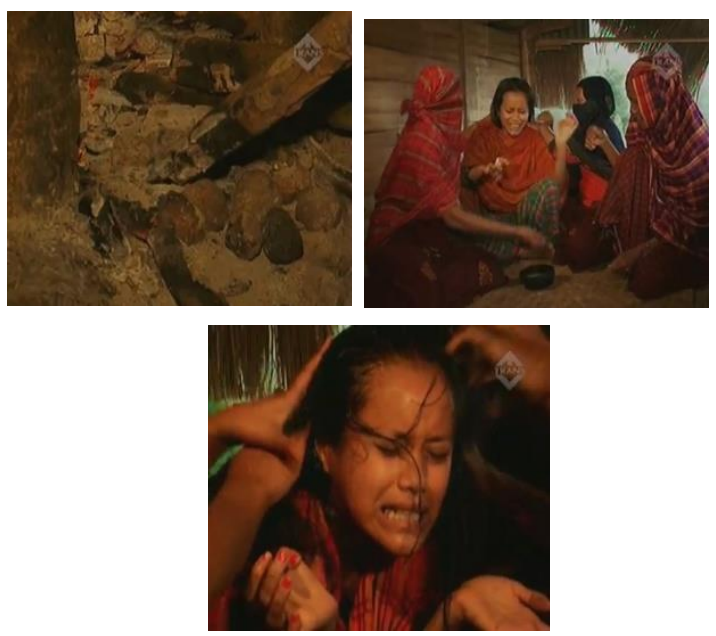

Time Code VCR : 00.28.00.25 -

$$
\text { 00.30.00.00 }
$$

\section{Analisis Denotasi}

Adegan ini memperlihatkan Lia Wa'ode membantu Ina Nur dan Wai Hai untuk membakar Biji Kemiri setelah itu Biji Kemiri di tumbuk kemudian kemiri di kunyah lalu di lepeh. Namun Lia yang terlihat reaksi menunjukkan jijik dalam pengambilan gambar saat Ina Nur meminta melepaskan Rimpu, kemudian lepehan Isukamii di oleskan di rambut kepala Lia. Tampak betapa kaku dan canggung, ditambah dengan keadaan terik-teriak. Long Shoot memperlihatkan suasana keadaan suku Sambori mengolesi Isukamii di kepala Lia.

\section{Analisis Konotasi}

Sistem semiologis tingkat kedua (the second order semiological system) menurut Barthes. Segmen 4 ini dengan menit 00.28.00.25 - 00.30.00.00 bahwa salah satu kebiasaan Suku Sambori, yakni Isukamii adalah ramuan tradisional alami penyubur rambut yang memakai Biji Kemiri setelah di bakar yang dipunyai kebudayaan kultural oleh Suku Sambori dalam perawatan rambut mereka.

\section{Simpulan}

Penelitian ini bertujuan untuk mengetahui etnis yang dipresentasikan melalui makna denotasi, konotasi, dan mitos serta ideologi yang muncul pada masyarakat Suku Sambori. Berdasarkan hasil analisis semiotika yang diadaptasi dari model semiotika Roland Barthes, dan menggunakan paradigma kritis terhadap tayangan televisi reality show Ethnic Runaway episode Suku Sambori sebagai subyek penelitian, hasil yang didapat menunjukkan bahwa terdapat lima adegan dalam tayangan tersebut yang dipakai sebagai leksia dalam penelitian ini yang 
secara khusus merepresentasikan etnis Sambori.

\section{Makna Denotasi, Konotasi, dan Mitos}

Setelah meneliti tayangan televisi "Ethnic Runaway" episode Suku Sambori, berdasarkan rumusan masalah, peneliti menemukan kesimpulan atas representasi etnis dalam tayangan ini, yaitu:

1. Berdasarkan tanda-tanda dominan yang muncul pada adegan-adegan tayangan ini, peneliti menemukan maknamakna denotasi, pertama yaitu Rio Dewanto dan Lia Wa'ode mencari tahu asal mula Rumah Lengge, kedua ialah Rio Dewanto menelusuri Tanah Keramat yang tidak boleh di injak, ketiga ialah jamuan makanan khas Suku Sambori Oi Mangge, keempat ialah Lia Wa'ode dan Rio Dewanto mencari kunyit untuk Encempe barter atau tukar dengan sayur mayur, dan kelima ialah kesenian tradisional dalam penyambutan tamu di Suku Sambori Pa Alanca.

2. Setelah melakukan penandaan tingkat pertama (denotasi) terhadap tanda-tanda yang muncul dalam tayangan ini, peneliti melakukan penandaan tingkat kedua yang menghasilkan makna konotasi, pertama yaitu kebiasaan atau tradisi Suku Sambori dengan adanya perbedaan, horor, dan mistis, kedua ialah tanah keramat yang sudah berpuluhan tahun, ketiga ialah pengolahan masak dalam Suku Sambori menjijikan dan tidak praktis, keempat ialah mencari kunyit dalam menghidupi keseharian dalam barter, dan kelima ialah tradisi Pa Alanca dengan adu betis dalam penyambutan tamu oleh tiga kaum lakilaki

\section{Daftar Pustaka}

\section{Buku}

Adorno, Theodor W. 1973. Negative Dialectics. Terjemahan E. B. Ashton. London: Routledge

Armando, Ade. 2011. Televisi Jakarta Di Atas Indonesia Yogyakarta: Penerbit Bentang

Barker, Chris. 2004. Cultural Studies, Teori \& Praktik. Bantul: Kreasi Wacana

Barthes, Roland. 1991. Mythologies. Terjemahan Annete Lavers. New York: The Noonday Press

Budiman, Kris. 2011. Semiotika Visual: Konsep, Isu, dan Problem Ikonisitas. Yogyakarta: Jalasutra

Chistomy, Yuwono, Agung. 2004. Semiotika Budaya. Depok : Pusat Penelitian Kemasyarakatan dan Budaya Univesitas Indonesia. 
Eriyanto. 2001. Analisis Wacana Mulyana, Deddy. 2001. Metode

Pengantar Analisis Teks Media. Yogyakarta: LkiS

Gunawan, Samuel .1999. Antropologi Budaya Suatu Perspektif Kontemporer. Jakarta : Erlangga.

Junaedi, Fajar, 2007. Komunikasi Massa : Pengantar Teoritis. Yogyakarta: Penerbit Santusta

Keesing, M. Roger, 1985. Anthropology A Contemporary Perspective : Second Edition Australia National University. Melbourne .

Koenjtraningrat., 1986. Pengantar Ilmu Antropologi . Jakarta : Aksara Baru Liliweri,Alo . 2001. Komunikasi Verbal Dan Nonverbal. Bandung : PT Citra Aditya Bhakti 2002. Makna Budaya dalam Komunikasi Antarbudaya. Yogyakarta: LkiS Yogyakarta

Martin, Judith N. \& Thomas K. Nakayama, 2007. Intercultural Communication In Contexts 4 th edition. New York: The McGrawHill
Penelitian Kualitatif. Bandung : Remaja Rosdakarya

\& Rahmat, J. 2005.

Komunikasi Antar Budaya:

Panduan Komunikasi Dengan

Orang-orang Berbeda Budaya . Bandung : PT Remaja Rosdakarya

Sobur, Alex .2006. Semiotika Komunikasi . Bandung : PT Remaja Rosdakarya.

\section{Artikel Jurnal di website}

Ananto, Sahrul Haetamy, 2010. Representasi Primitif dalam Program Runaway Episode Suku Rimba di Trans TV, sebuah analisis Semiotika model Roland Barthes terhadap penggambaran Primitif dalam Program Primitive Runaway Episode Suku Rimba.

Komisi Penyiaran Indonesia (Lembaga Negara Independen). 2012. Pedoman Perilaku Penyiaran (P3) dan Standar Program Siaran (SPS) 